\title{
Four indices of domestication in Norway rats
}

\author{
CARROLL W. HUGHES, ANITA V. SETTLE, and ROBERT BOICE \\ University of Missouri, Columbia, Missouri 65201
}

\begin{abstract}
Reactivity to handling by an experimenter was predictably greater in wild rats than in domestic counterparts (Rattus norvegicus); this emotionality also diminished in certain critical aspects for wild rats over time. A second index from the pioneering research by Stone (1932), concealment in a stovepipe maze, also discriminated well but proved impractical and apparently confounded. The third, more objective index was a test involving water consumption. This too discriminated well; the wild rats drank more. A fourth and most contemporary index of domesticity compared the two kinds of rats' swimming to the edge of a pool. Here again wild rats were more reactive and more efficient in escaping from the water.
\end{abstract}

Origins of domesticated rats are a mystery. since there are no records of early techniques in domesticating laboratory rats from their progenitors, wild Rattus norvegicus, some 100 years ago (Richter. 1954). Moreover, nothing substantive is known of exact parental stock or how selective breeding contributed to these traditionally popular subjects for research (Boice, 1971b).

Contemporary attempts to understand the process of domestication in the Norway rat emphasize comparisons of wild and domestic rats (Barnett. 1975; Boice, 1972). Some refute criticisms that domestication has induced degeneracy in the laboratory rat (Hughes \& Boice, 1973). To date, however, little has been done to systematically map behavioral differences between domestic and wild rats. This may reflect the lack of standardized indices of domestication for Norway rats. While it seems obvious that domestication has significantly changed laboratory rats, supportive evidence is but preliminary (Boice. 1973). Accordingly, little agreement exists concerning how potential differences between wild and domestic rats should be measured.

The present experiments test four indices of domestication based on established assumptions of how wild and laboratory rats differ. Two of these assumptions reflect the earliest researches on wild rats in psychology; as such, they need replication and clarification. The other two represent more recent concerns of objectivity and relevance to "naturally occurring" behaviors. Our goal was to begin ascertaining which indices can be used to measure effects of domestication, especially in tests of captive rats over many generations. In view of the immense investment required in such long-term research, we started with the assumption that even classic indices must be reexamined.

\section{EXPERIMENT I: CONCEALMENT TEST}

A classic index of domesticity is Stone's (1932) study of concealment in a stovepipe apparatus. The rationale is based on his observation that captured wild rats tend to crouch against the walls of their cages or to seek cover when opportunity for concealment is offered. Concealment obviously seems a response that diminishes with domesticity in Norway rats.

The present study is a replication and extension of the classic study. Changes from the original include unobtrusive observation, more detailed testing, and a condition intended to reduce the confounding of startling the wild rats into complete inaction.

\section{Method}

Subjects and design. Subjects were females from two stocks of Norway rats (Ruttus none'gicus). 12 laboratory reared wild rats of the first generation in captivity, and 12 hooded domestic rats of Long-Evans stock (150-180 days old). The design was a 2 by 2 by 2 factorial (cross-fostered vs. normal reared, hooded vs. wild stock. and buzzer vs. no buzzer).

Apparatus. The dimensions of the apparatus replicated those of Stone (1932). In place of the original metal stovepipe, opaque black plastic pipe was used. Remotely operated guillotine doors separated the U-shaped tunnel from the start- and goalboxes; both of the boxes were covered with clear Plexiglas. An Akai video camera was mounted directly over the apparatus to allow remote initiating and scoring of trials.

Procedure. Litters were reduced to eight at birth. with four males and four females where possible. The litters were either raised normally by wild-caught and domestic mothers or cross-fostered to a mother of the opposite stock. On Day 21 the litters were weaned. and the subjects were then individually housed with food and water ad lib.

Five trials were run, one each day for a 5-day period. The times to leave the startbox ("start" score) and the times elapsed from leaving the startbox to entering the goalbox ("goal" score) were recorded. To get to the food at the end of the goalbox (Purina Lab Chow), half the subjects had to cross a treadle, which activated a microswitch. setting off a $110 \mathrm{~V}$ door buzzer in replication of Stone's (1932) procedure. Since the apparent aversiveness of the buzzer may have accounted for Stone's finding that wild rats were more timid. half of our subjects were run without the buzzer. The paradigm and criteria for trials followed King's (1970) procedure with domestic rats.

\section{Results and Discussion}

An analysis of variance revealed no significant main effects or interactions for start latencies. The analysis 
for goal latencies indicated domestic rats $(\bar{X}=$ $262 \mathrm{sec})$ have shorter latencies than wild subjects $(\overline{\mathrm{X}}=804 \mathrm{sec})[\mathrm{F}(1,16)=7.67, \mathrm{p}<.025]$ and a main effect for Days $[F(4,64)=4.80, p<.01]$.

As in Stone (1932), the results seem to show a clear hiding tendency by wild rats compared to domestic rats. The question is, in part, whether this technique is a meaningful behavioral index for wild rats who essentially stopped performing. We had hoped to diminish this factor with two changes from Stone's (1932) study; but neither unobtrusive observation via a television monitor nor removal of the raucous buzzer produced a change from his results. In a sense, this is a clear index of domestication, because it discriminates so well. But in practice it is an awkward test (see General Discussion).

\section{EXPERIMENT II: REACTIONं TO HANDLING}

Stone's (1932) classic study included a second obvious test for effects of domestication, reactions of rats to handling by a human experimenter. Stone expanded Yerkes' five-point rating scale (Yerkes, $1913)$ to 11 items, the first six denoting "wildness," the rest "savageness." While cautioning against the arbitrary and subjective weaknesses in this measure, Stone carefully detailed the procedure for rating each of the 11 items over 10 days. Differences between the wild rats and a variety of "relatively gentle" groups were large and reliable. Perhaps because of cautions cited by Stone, this index of domestication has not been used subsequently.

Experiment II resurrects Stone's technique, since it is still the only extensive test available for this clearly important aspect of domestication in rats. We thus followed his example in two respects: We fully realized its definitional and subjective limitations, and we arbitrarily changed a few things. We dropped one of his items, that of catching the rat in its home cage, since this was contrary to the partially mechanized handling procedure we used. And we added two others, grooming and jumpiness. Grooming can be considered a relaxational response; it often comes in the transition between freezing and other behaviors (Hinde, 1970). Jumpiness is defined as an obvious leap by a rat in response to a sudden, loud noise.

\section{Method}

Subjects. The subjects were 10 Long-Evans females (150 days old) and 10 wild-caught Rattus norvegicus adult females.

Procedure. The rats were removed from their home cages with a plastic handling box. Once the sliding floor of the handling box was closed, the box was moved to a counter and a 1-min assessment of the rat's behavior was made. Next, the floor was opened slightly to allow the rats to run into a terry cloth bag $(27.5 \times 22 \mathrm{~mm})$. The rat was then grasped and the bag peeled back to expose the rat; rats were held briefly and then returned to their home cages. Ratings for each of the 12 items were based on behaviors of each rat in the handling box and in the handling sack. These were repeated for 32 consecutive days. although analysis as presented here is based on the first 12 days and the 30 th day.
Using Stone's system, we rated each item on appoint scale, usually from 0 to 3 . The exceptions were defecation and grooming, which had a range of $0-1$ : that is. they either happened or they did not. The zero point ideally represented the behavior of a perfectly tame rat. whereas value 3 was supposed to indicate maximally undomesticated behavior. As in Stone's study, end points of the rating scales were frequently reestablished by comparing behaviors of docile laboratory rats with those of an apparently excited wild rat.

\section{Results and Discussion}

Although this measure is rather subjective, the results closely parallel Stone's. As in the classic research, the domestic rats nearly always rated zero on each item, so much so that presentation of their homogeneous data would convey little information.

The important finding is that the wild rats habituated in many of the items over the 30 days of handling. Even so, several of the items continued above the levels of the domestic rats. It is curious to note that what Stone classified as savageness (Items 6-10) waned or became "more domestic" (mean for hissing dropped from .9 to 0 ), while those in the wildness category (Items 1-5) did not (mean for squirming dropped from 3.0 to 2.0 ). So, even after 30 days of handling, wildness components such as tenseness and squirming continue at an intermediate level.

\section{EXPERIMENT III: WATER CONSUMPTION}

The first two experiments are characteristic of the older indices of domestication in Norway rats; they differentiate decisively but they are subjective and difficult to use. More recent indices are often more practical and objective. One of these is a measure of water consumption as an index of emotionality. The rationale has origins in studies showing that water consumption increases after aversive stimulation (Siegel \& Siegel, 1949). The allied assumption is that more emotional wild rats should consume more water in captivity than their domestic counterparts (Richter, 1954). Recent research (Boice, 1971a) suggests that normal wild rats consume more than domestic rats until the former are acclimatized in captivity.

The present experiment is unique as a test of domestication in that it returns to a technique popular a few years ago in eliciting emotionality. This is a comparison of water consumption as affected by electric shock.

\section{Method}

Subjects and design. The subjects were females from two stocks of Norway rats (Rattus norvegicus), 20 laboratory reared wild rats of the first generation in captivity, and 20 hooded domestic rats of Long-Evans stock (120-150 days of age). The design was a 2 by 2 factorial (cross-fostered vs. normal reared. hood vs. wild stock) with days as a repeated factor.

Apparatus. To administer shock to the subject within its home cage, a device was made consisting of two metal probes $(1 \mathrm{~mm}$ in diam). $6 \mathrm{~mm}$ apart, which extended $13 \mathrm{~mm}$ from the end of a wood dowel. A handle which held the prod also contained a switch for activating the shock through the probes. The shock power source consisted of $110 \mathrm{~V} .60 \mathrm{cps}$, and was wired directly through a Hunter 
interval timer such that a .25 -sec shock could be delivered.

Procedure. The animals from 20 litters were equally distributed across conditions (rearing procedures same as Experiment I). Daily water consumption was measured for a 2 -week period, and converted to a grams/body weight ratio for each animal. On the 14th day all animals received a brief, very intense shock while in the home cage. Four days later. one half of these subjects received a second shock similar to the first. Water consumption was monitored for an additional 7 days.

\section{Results and Discussion}

Days 1 through 14 served as a baseline of daily water consumption. Analysis of variance of Days 1 through 9, with days as a repeated measure, indicated that wild rats were consuming significantly more water than domestic rats $[F(1,16)=7.51, \mathrm{p}<.05]$ and that days differed from each other $[F(8,128)=$ $3.04, p<.01]$. These findings and the daily water consumption for the entire period are depicted in Figure 1.

Analysis of variance for Days 10 through 18 indicated only a main effect for shock $[F(1,16)=$ $11.57, \mathrm{p}<.01$ ]; wild rats consumed more water than domestic rats. Analysis of variance for Days 19 through 25 included the second shock as an additional factor. Again, wild rats consumed more water than domestic rats $[F(1,16)=6.65, p<.05]$ and days differed $[F(6,192)=2.90, p<.01]$.

As a group, the wild rats drank more than the domestic rats. This is another confirmation of Richter's (1954) notion that wild rats drink more because they are more emotionai (cf. Hughes, 1975). The large difference in water consumption by wild rats on Day 21 suggests either a delayed response to the second shock or, more likely, anticipation of a third. These findings merit further study and indicate the potential use of this test of domesticity.

\section{EXPERIMENT IV: WATER ESCAPE}

Experiments I, II, and III might be criticized because the laboratory setting for each has limited relation to events occurring in the natural habitat of Norway rats. Wilcock (1972) has proposed water escape as a behavioral test linked to biological fitness in Rattus norvegicus. Musing upon events in nature, such as a rat's falling into water with the crumbling of a riverbank, Wilcock assumes that natural selection has favored rats that escape quickly and efficiently from the water. Curiously, Wilcock did not test wild rats. Rather, he used weanling domestic rats, assuming that natural selection acts most critically at this age.

Experiment IV is an extension of Wilcock's (1972) test to wild and domestic rats, including both weanling and adult rats. Since domestication may bring a release from some natural selection pressures (Boice, 1973; Ratner \& Boice, 1975), domestic rats might be less capable in this aspect of biological fitness. Alternatively, the water escape test could be viewed as an index of emotionality; the more reactive wild rats would be expected to escape more quickly.

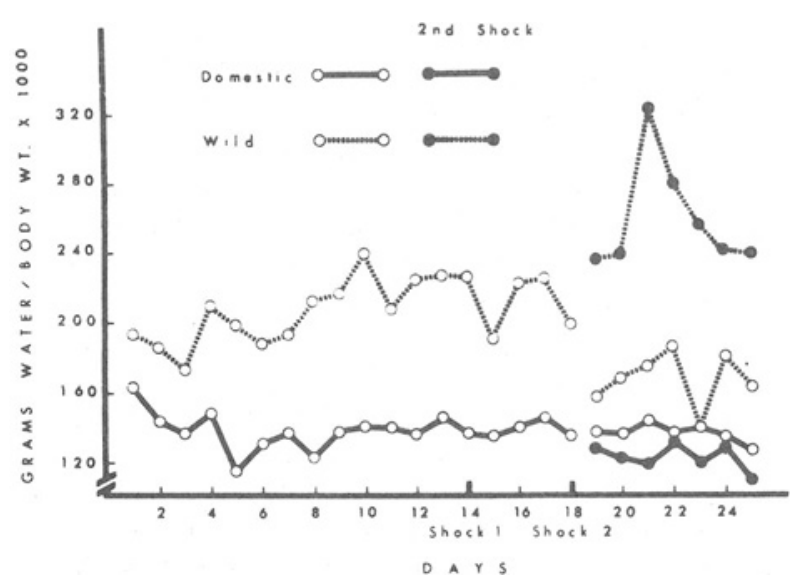

Figure 1. Means of daily water intake ratios (based on the weight of water consumed divided by body weight and multiplied by a factor of 1,000 ) for hooded domestic rats and wild rats (Experiment III). The heavy vertical lines indicate the occurrence of a first (Day 14) and a second (Day 18) electric shock. The second shock was administered to only half the animals in each group; animals that received the second shock are signified by solid circles beyond Day 18 .

\section{Method}

Subjects. In the first subtest, the subjects were 10 domestic Sprague-Dawley adults (from 5 different litters), 10 domestic Sprague-Dawley 21-day-old weanlings (from 5 different litters), 10 wild-caught Rattus norvegicus adults, and 10 first-generation laboratory reared 21-day-old weanling wild rats (from 4 different litters). Each group was equally divided between males and females.

In the second subtest, the subjects were two groups of male Norway rats, 16 first-generation laboratory reared wild rats and 16 domestic rats of Sprague-Dawley stock. Half these animals had been handled and half had not (see Hughes, 1975 for procedural details). The expectation was that handling, especially in the wild rats, would render the animals less reactive to the test situation.

Apparatus. The water escape test and apparatus were similar to those described by Wilcock (1972). The apparatus was a plastic pool $121 \mathrm{~cm}$ in diam filled with water to a depth of $20 \mathrm{~cm}$. Wire mesh with $.5-\mathrm{cm}$ squares was molded around the perimeter of the pool and extended below the water line to allow the rats footing for climbing out. Centered over the pool, with the floor $25 \mathrm{~cm}$ above the water, was a $13.7 \times 21.0 \times 13.0 \mathrm{~cm}$ deep wood box. This box had a metal lid and a sliding metal floor that could be completely pulled out from under the rat.

Procedure. Adults were at least 150 days old when tested, and the weanlings were tested at 21 days for domestic rats and at approximately 26 days for laboratory reared wild rats. The water escape test consisted of six consecutive trials in which the subject was dropped into the pool of water. Latency from the time the floor was pulled out from under the rat until the rat touched the edge of the pool was recorded for each trial.

\section{Results and Discussion}

Two separate designs were used. In the first, a 2 by 2 (adult vs. weanling age, albino vs. wild stock, and trials as a repeated measure) analysis of variance was employed. Wild rats had a significantly shorter escape latency than domestic rats $[\mathrm{F}(1,36)=7.84$, $\mathrm{p}<.01]$.

There is evidence here that "wilder" or more emotional rats escaped more quickly. This is in accord with either notions of biological fitness or emotionality. As in Wilcock (1972), latencies for domestic weanlings dropped sharply after the first trial. But the 
finding is not general; latencies for the older domestic rats tended to increase over trials [Age by Stock by Trial. $F(5.180)=4.16, p<.01]$.

The second test was factorial (handled vs. nonhandled, albino vs. wild stock, and trials as a repeated measure). Its purpose was an additional test of adult rats; the first finding was replicated, this time with laboratory reared wild adults. The addition of handling was also a significant factor. Analysis of variance of the water escape latencies with trials as a repeated measure indicated a Handling by Stock by Trial interaction, $F(5,20)=11.7, p<.01$. Except for the consistent effect of stock over trials, the initial trial revealed the main distinction between groups and treatments. The nonhandled rats escaped more quickly than the less emotional, handled rats, replicating the previous study and extending the notion of more emotional rats escaping more quickly.

Observations of swimming behaviors indicated qualitative differences; wild rats reached the edge of the pool faster than domestic rats but spent more total time in the water. Typically, a wild rat surfaced immediately after being dropped into the water and swam in a straight path to the edge. After touching the edge. the wild rat dove to the bottom of the pool and swam along the side underwater. Several adult rats spent $30 \mathrm{sec}$ or more below the surface. In contrast, domestic rats did not spend much time underwater but swam in circles on the surface before touching the side.

\section{GENERAL DISCUSSION}

The four experiments presented here, while only exploratory, represent two relatively unique approaches to the study of domestication in the Norway rat. First. the range of indices of domesticity is unusually broad; it includes cross-sectional and lengthy testing. as recommended by Archer (1973) for tests concerning emotional behaviors. Second, these experiments mirror historical trends in this research area. In the first two experiments. inspiration comes from early reports where relatively subjective measures were favored. The third represents the shift toward objectivism in psychology. And the fourth is contemporary in emphasizing supposedly ecological relevant behaviors.

The results suggest that three of the four indices used here may be suitable: for longitudinal research on domestication. Water consumption as an index discriminated reliably between wild and laboratory rats: water escape produced results analogous to water consumption. Both this and the handling tests of reactivity appear to be legitimate indices of domestication in these admittedly small samples of Norway rats. They represent this sample of wild rats as more reactive than their domestic counterparts. Moreover, these indices discriminate while eliciting performance from the sometimes uncooperative wild rat. Other indices of domestication might be valid in showing little or no difference in behavior of wild and domestic rats (Boice. Note 1; Hughes. Plaut, \& Harlan, Note 2).

Actually. the remaining index, concealment pitted against hunger. discriminated most clearly; the difference was the result of complete inaction by most of the wild rats (cf. Hughes, 1976). This tendency to concealment did not diminish over repeated trials or days. so the suggestion is that this is too crude an index to be used to detect small changes in domesticity over many generations. Certainly. this is a trying technique for both the experimenter and wild rats. It was the classic stature of this technique (Robinson. 1965) which necessitated its comparison with other indices.
It is fitting that the great pioneer Stone (1932) should have the concluding words: "In studies of wild ness and savageness, however. as in other studies of the emotions, acceptable experimental situations are difficult to standardize and indexes seem equivocal. Hence. one should be prepared to expect that many pioneer studies of these traits must be made before any but the most tentative conclusions may be reached concerning their hereditary foundations. humoral dependency, relationship to other modes of behavior in experimental situations, etc. “ (p. 3).

\section{REFERENCE NOTES}

1. Boice. R. A test for degeneracy in laboratory rats: Indoor and outdoor burrowing by wild and domestic Norway rats. Paper presented at the meeting of the Psychonomic Society, Boston, 1974.

2. Hughes, C. W.. Plaut, S. M., \& Harlan, R. S. Maternal behavior of wild and domestic rats (Rattus norvegicus) in dualchambered cages allowing continuous recording. Paper presented at the meeting of the Animal Behavior Society. Wilmington, 1975.

\section{REFERENCES}

ARCher. J. Tests for emotionality in rats and mice: A review. Animal Behavior. 1973, 21, 205-235.

BarnetT. S. A. The rat. Chicago: University of Chicago Press. 1975.

BoICE. R. Excessive water intake in captive Norway rats with scar-markings. Physiology and Behavior, 1971, 7 , 723-725. (a)

BoICE. R. Laboratorizing the wild rat (Rattus norvegicus). Behavior Research Methods \& Instrumentation, 1971, 3. 177-182. (b)

Boice, R. Some behavioral tests of domestication in Norway rats. Behaviour. 1972, 42. 198-231.

B̈oICE, R. Domestication. Fsychological Bulietin, $1 \overline{4} 73,80$. 215-230.

Hinde. R. A. Animal Behaviour. New York: McGraw-Hill, 1970.

Hughes. C. W. Early experience in domestication. Journal of Comparative and Physiological Psychology, 1975, 88, 407-417.

Hughes. C. W. Shock vs. ice-water passive avoidance learning in wild and domestic Rattus norvegicus. Animal Learming \& Behavior. 1976, 4, 66-70.

Hughes. C. W.. \& Boice, R. Avoidance, one and two way, in wild and domestic Norway rats. Journal of Comparative and Physiological Psychology, 1973. 84, 408-413.

KING, D. L. Effect of early experience and litter on some emotionality variables in the rat. Journal of Comparative and Physiological Psychology. 1970, 73, 436-441.

RATNER, S. C., \& BoIce, R. Effect of domestication on behavior. In E. S. E. Hafez (Ed.). The behavior of domestic animals (3rd ed.) Baltimore: Williams \& Wilkins, 1975.

Richter. C. P. The effects of domestication and selection on the behavior of the Norway rat. Journal of National Cancer Institute, 1954, 15, 727-738.

Robinson, R. Genetics of the Norway rat. Oxford: Pergamon Press, 1965.

Siegel, P. S., \& Siegel. H. S. The effect of emotionality on the water intake of the rat. Journal of Comparative and Physiological Psychology, 1949, 42, 12-16.

Stone. C. P. Wildness and savageness in rats of different strains. In K. S. Lashley (Ed.). Studies in the dynamics of behavior. Chicago: University of Chicago Press, 1932.

WILcock, J. Water-escape in weanling rats: A link between behavior and biological fitness. Animal Behavior, 1972, 20. 543-547.

YERKES, R. M. The heredity of savageness and wildness in rat. Journal of Animal Behavior, 1913, 3, 286-296.

(Received for publication March 26, 1976; revision received July 6,1976 .) 